\title{
Beyin Tümörlerinin Cerrahi Planlamasında Difüzyon Tensör Görüntülemenin Katkısı
}

\author{
The Efficiency of Diffusion Tensor Imaging in Preoperative Arrangement of Brain Tumors
}

Diğdem Kuru Öz' , Elif Peker², İlhan Erden²

1 Özel Polatlı Can Hastanesi Radyoloji Bölümü
2 Ankara Üniversitesi Tıp Fakültesi Radyoloji Anabilim Dalı

Geliș Tarihi : 30.08.2016• Kabul Tarihi: 19.09.2016

Iletișim

Dr. Diğdem Kuru Öz

E-posta: digdem@hotmail.com

Tel: 03126214141

Faks: 03126210757

Özel Polatlı Can Hstanesi Radyoloji Anabilim Dalı Yeni Mah.

Gordion Cad. No:1 Polatlı/Ankara

Amaç: Cerrahi yapılan beyin tümörlü hastaların patoloji sonuçları, klinik muayene bulguları ve preoperatif Difüzyon Tensör Görüntüleme (DTG) özellikleri ile birlikte değerlendirilerek, DTG'nin tümör ile komșu beyaz cevher yolaklarının ilișkisini ameliyat öncesi ortaya koyabileceğinin gösterilmesi amaçlanmaktadır.

Gereç-Yöntem: Bu araștırmada 26 hastaya ait 54 etkilenmiș yolak ve 54 kontralateral hemisferik yolak değerlendirildi ve Fraksiyonel Anizotropi (FA) ölçümleri yapıldı. Beyaz cevher yolakları direkt renk kodlu haritalar kullanılarak ödem, yer değiștirme, infiltrasyon ve destrüksiyon șeklinde kategorize edildi. Kategorize edilen gruplar arasındaki FA değișimleri ( $\triangle \mathrm{FA} \%)$ istatistiksel olarak karșılaștırıldı. Ödem ve yer değiștirme grubuna ait yolaklara sahip olan ve ameliyat yapılan hastalar operasyon sonrasında klinik olarak değerlendirildi.

Bulgular: Ödem, infiltrasyon ve destrüksiyon gruplarında $\triangle F A \%$ değeri anlamlı bulunmuștur. Hem ödem hem destrüksiyon grubundaki FA değeri yer değiștirmeden küçüktür. \%30'dan küçük $\Delta F A \%$ değerinin, infiltrasyon ve destrüksiyon ile ilișkili olması muhtemeldir. Pozitif $\Delta \mathrm{FA} \%$ değerinin, ödem veya yer değiștirme ile ilișkili olması muhtemeldir. Ödem ve yer değiștirme grubundaki hastalarda postoperatif ek nörolojik defisit gelișmemiștir.

Sonuç: Beyin tümörlü olgularda preoperatif difüzyon tensor görüntüleme ile kitle ve komșu beyaz cevher yolaklarının ilișkisini değerlendirmeyi amaçlamıș ve preoperatif DTG ile etkin bir cerrahi planlamanın mümkün olabileceği sonucuna ulașılmıștır.

Anahtar Sözcükler: Beyin Tümörü, Difüzyon Tensör Görüntüleme, Fraksiyonel Anizotropi

Aim: It is intended to be revealed the relationship between tumor and adjacent white matter tract preoperatively by Diffusion Tensor Imaging (DTI), with evaluation of pathology results, clinical examination results and preoperative DTI characteristic of surgery performed brain tumor patiens.

Materials-Methods: In this study, 54 leison sided white matter tract and 54 contralateral white matter hemispheric controls belongs to 26 patient was examined and Fractional Anisotropy (FA) measurement was perfomed. White matter tracts was categorized as edema, displacement, infiltration and disruption with using directionally encoded color maps. FA changes $(\triangle \mathrm{FA} \%)$ between categorized groups was compared by statistically. Patients that have displaced and edematous white matter tract and also gone surgery were assessed clinically after surgery.

Results: $A$ significant $\triangle F A \%$ was found in edema, disruption and infiltration groups. Both edema $F A$ and disruption FA are significantly less than displacement FA. $\triangle F A \%$ less than $-30 \%$ is likely to be associated with disruption and infiltration. A positive $\triangle \mathrm{FA} \%$ is likely to be associated with edema or displacement. The patients in edema and displacement groups has not developed additional postoperative neurologic deficits.

Conclusion: In patienst with brain tumor aimed to assess the relationship of mass and adjacent white matter tracts with preoperative diffusion tensor imaging and reached the conclusion that it is possible to effectively surgical planning with preoperative DTI..

Key Words: Brain Tumour, Diffusion Tensor Imaging, Fractional Anisotropy

Cerrahi nöroonkolojide maksimum tümör rezeksiyonunun yanında vital serebral dokunun korunmasi temel prensiptir(1-4). Konvansiyonel MR tetkikleri ile beyin tümörünün varllğ 1 ve lokalizasyonu kolaylıkla saptanırken tümöre komşu beyaz cevher yolakları ile ilgili bilgi edinilemez $(1,5)$. Difüzyon Tensör görüntüleme (DTG), beyin tümörüne komşu beyaz cevher yolaklarını değerlendirmede yakın dönemde kullanılan yeni bir yöntemdir (1-3,5).

DTG tekniğinin temeli su moleküllerinin in-vivo difüzyon hızının ve yönünün ölçülerek doku yapısının saptanmasina dayanır $(2,5,6)$. Moleküllerin üç boyutlu ortamda yaptıkları 1sı bağıml serbest harekete 'Brownian hareket' denilmektedir. Bu şekilde moleküllerin her yöne eșit olarak yaptığı serbest 
difüzyona 'izotropik difüzyon' denilmektedir. Su moleküllerinin yaptıkları bu Brownian hareketin her üç yöndeki bileşeninden bir ya da daha fazlasinın, dokudaki bir takım anatomik ya da fizyolojik engeller nedeniyle kisitlanmasi 'anizotropi' olarak adlandirılır. DTG, üç boyutlu ortamda bir vektör boyunca su difüzyonunun yönü (anizotropi) ve büyüklüğü (difüzivite) hakkında kantitatif ve kalitatif bilgiler sağlamaktadır (7). Bu izotropi ve anizotropi verileri, $\mathrm{ADC}$ ve FA değerleri ile belirtilmektedir. ADC; dokudaki izotropi miktarını, FA; dokudaki difüzyonun anizotropik kısmının tüm difüzyona oranını temsil eder. Beyaz cevher gibi anizotropik difüzyonun baskın olduğu dokularda FA değerleri kullanılır (1). Bizim çalışmamızda da, tümöre komşu beyaz cevher yolaklarının etkilenme șekli, direkt renk kodlu haritalarda FA değerleri kullanılarak belirlenmiştir.

\section{Gereç-Yöntem}

Ankara Üniversitesi Tip Fakültesi Radyoloji bölümünde, 2010 ile 2011 tarihleri arasinda 3 Tesla MRG sisteminde (Magnetom Verio, Siemens, Erlangen, Almanya) beyin tümörlü 26 hasta değerlendirilmiştir. Yirmialtı hastada 54 etkilenmiş beyaz cevher yolağ1 tespit edilmiştir.

Difüzyon Tensör Görüntüleme, standart parametreler ile $(\mathrm{TR} / \mathrm{TE}=3600 / 95$,

A)

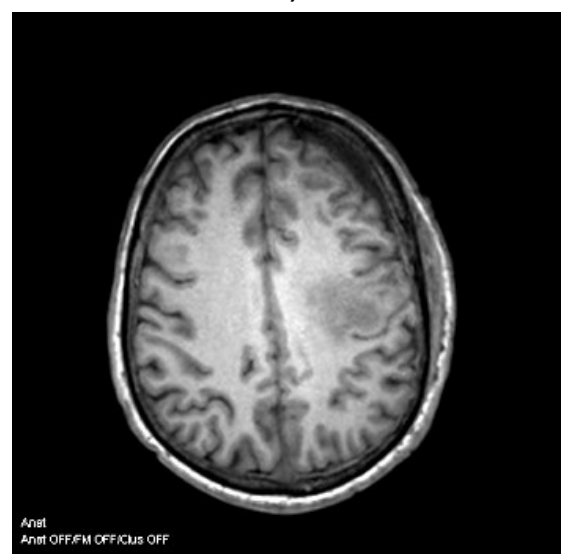

$\mathrm{FOV}=23 \mathrm{~cm}$, matriks $=128 \times 128)$ single-shot spin-echo EPI sekans kullanılarak yapılmıştır. Kesit kalınlığ 4.0 $\mathrm{mm}$ ve aralığ1 $1.2 \mathrm{~mm}$ olup ortalama 25 görüntü oluşmuştur. Difüzyon duyarlı gradient kodlama, difüzyon ağırliklı faktör b değeri $1000 \mathrm{~s} / \mathrm{mm}^{2}$ ile 64 yönde uygulanmıştır.

Patoloji sonuçları baz alınarak FA haritaları ile major eigen vektör yönü kullanilarak beyaz cevher yolakları 4 paterne kategorize edilmiştir. Yön haritası, kırmızı, yeşil ve mavi renkler ile kodlanan major eigen vektör komponenti tarafindan oluşturulmakta olup renk parlaklığını FA değerleri belirlemektedir. Her yolağın lokalizasyonu ve renk tonu doğrultusal renk kodlu haritada karşı sağlam yolak ile karşılaştirilarak normal veya anormal olarak sınıflandirılmıştır. Ayrıca kantitatif analizler, 2 boyutlu FA haritasinda incelenecek yolak üzerinde ve kontral hemisferdeki karş1lığ yolaktan manuel olarak çizilen 'Region of Interest' (ROI) ile Neuro 3D software yardımı ile yapılmıştır.

Beyaz cevher yolakları ödem, yer değiştirme, infiltrasyon ve destrüksiyon olarak kategorize edilmiştir. Kontralateral hemisferdeki homolog trakt ile karş1laştırıldığında FA değerleri normal veya hafif düşük $(<\% 25)$ ve trakt anormal lokalizasyon ve/veya yöndeyse yer değiştirme olarak sınıflandı-

rllmıştır. Ödem ve infiltrasyon paternlerinin her ikisinde de FA değerleri düşük kabul edilirken ayrım doğrultusal renk kodlu haritalardan yapılmıştır. Trakt normal lokalizasyon ve oryantasyonda iken renk tonları normal ise ödem, renk tonunda farklilik olduğunda infiltrasyon grubunda kabul edilmiştir. İzotropik veya izotropiye yakın difüzyonun olduğu traktların seçilemediği olgular destrüksiyon grubuna dahil edilmişlerdir (Şekil 1-4).

Ayrıca $\Delta \mathrm{FA} \%$ olarak adlandırılan, kontralateral normal hemisfer ile karşılaştırıldığında etkilenmiş taraftaki tümöre komşu beyaz cevherdeki FA değişimi hesaplanmıştır.

$\Delta \mathrm{FA} \%=\underline{\mathrm{FA}(\text { etkilenmis taraf)- } \mathrm{FA} \text { (normal) }} \times 100 \%$ $\mathrm{FA}$ (normal)

İstatistiksel olarak etkilenmiş taraftaki ve normal hemisferdeki FA değerleri tahmini marjinal ortalama $\pm \mathrm{SH}$ (standart hata) olarak gösterilmiştir. Tekrarlanan ölçü faktörü içeren ANOVA analizi kullanılmıştır. Hem yolaklar hem de etkilenmiş taraflar tekrarlanan faktörler olarak ele alınmıştır. p değerinin 0.05 'in altunda olması istatistiksel olarak anlamlı kabul edilmiștir.

Ameliyat yapilan hastalar operasyon sonrasında klinik muayene bulguları ile tekrar değerlendirilmiştir.

B)

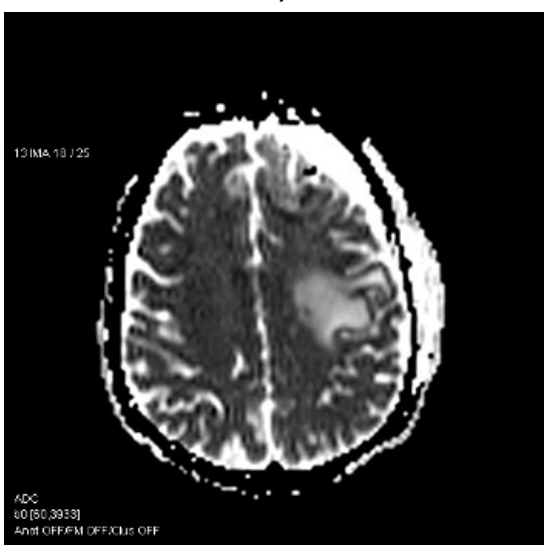

C)

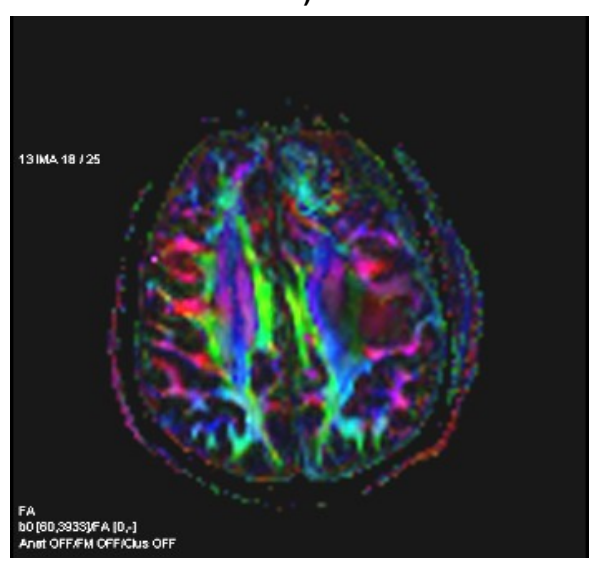

Şekil 1: Sol frontoparietal yerleşimli nöroendokrin tümör metastazı, sol süperior fasikulusda (SLF) ödem

A) T1 ağırlıklı görüntülerde subkortikal yerleşimli hipointens kitle

B) ADC haritalarında kitle çevresinde hiperintesite

C) Doğrultusal renk kodlu haritada sol SLF'de simetriğine oranla FA değerlerinde belirgin değişiklik saptanmamıştır (sağ-0.495,sol-0.490) 
A)

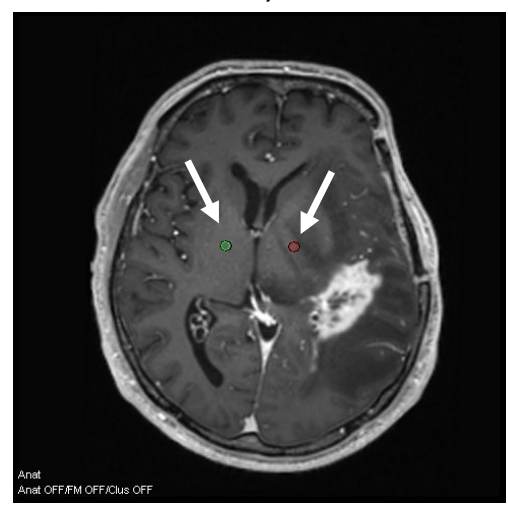

B)

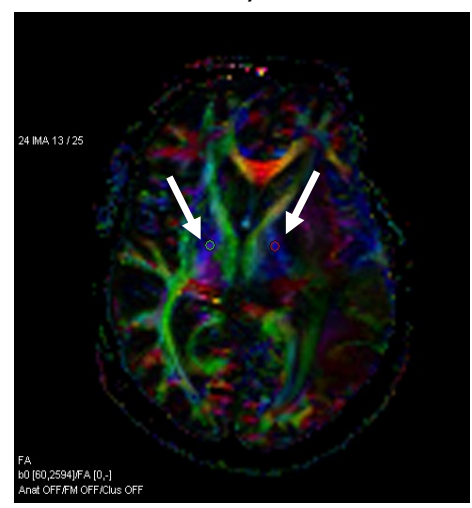

C)

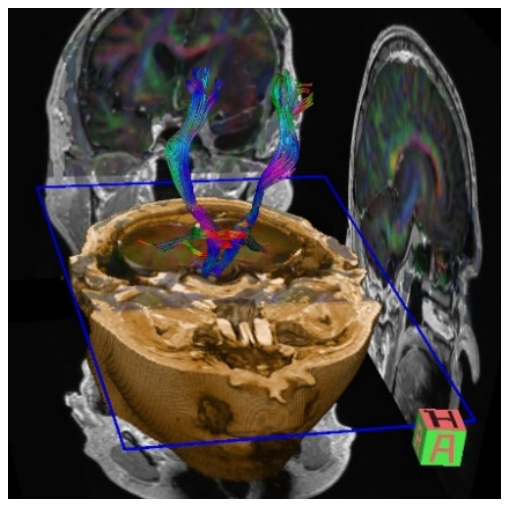

Şekil 2. Sol temporoparietal yerleşimli nüks Glioblastome multiforme (GBM), kortikospinal traktta (KST) yer değiştirme

A) Kontrastlı T1 ağırlıklı görüntülerde periferal hipointensitenin eşlik ettiği kitle

B) Doğrultusal renk kodlu haritada sol KST normal lokalizasyon ve oryantasyonda değildir. Yapılan FA ölçümlerinde simetriğine oranla belirgin farklılık (sağ- 0.722, sol-0.713)

C) 3D Traktografide sol KST'de yer değiştirme

A)

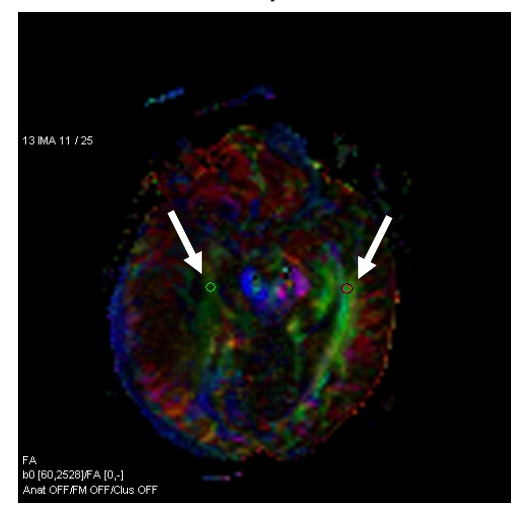

B)

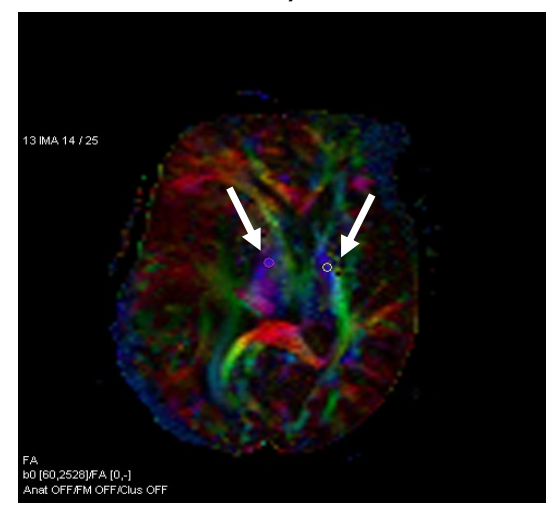

C)

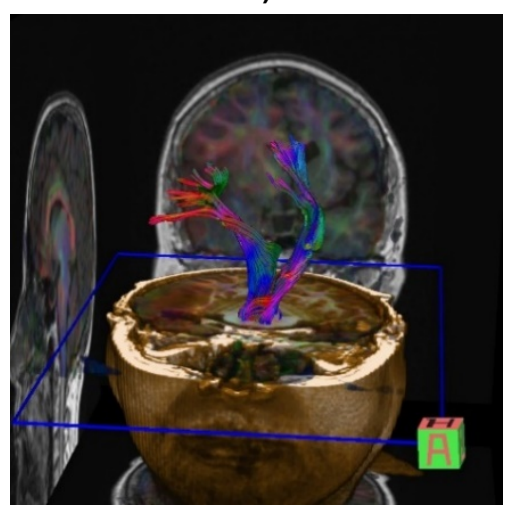

Şekil 3: Sağ temporoparietalde GBM, sağ İnferior longitudinal fasikulus (ILF) infiltrasyon, sağ KST'de yer değiştirme.

A) Doğrultusal renk kodlu haritada sağ íLF normal lokalizasyonunda ve seçilebilmekte ancak parlaklığı simetriğine oranla azalmış, FA ölçümlerinde oranla belirgin derecede azalma mevcut (sağ-0.293, sol-0.573).

B) Direkt renk kodlu haritada sağ KST simetriğinle benzer parlaklıkta ancak anormal lokalizasyonda, yapılan FA ölçümlerinde belirgin değişiklik (sağ-0.763, sol-0.762).

C) 3D Traktografi görüntülerinde sağ KST'de mediale itilme

A)

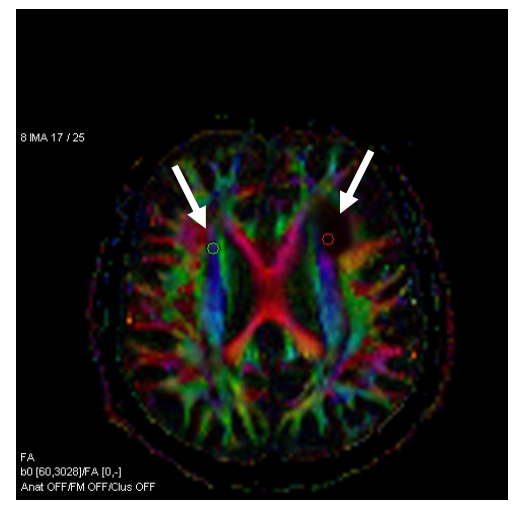

B)

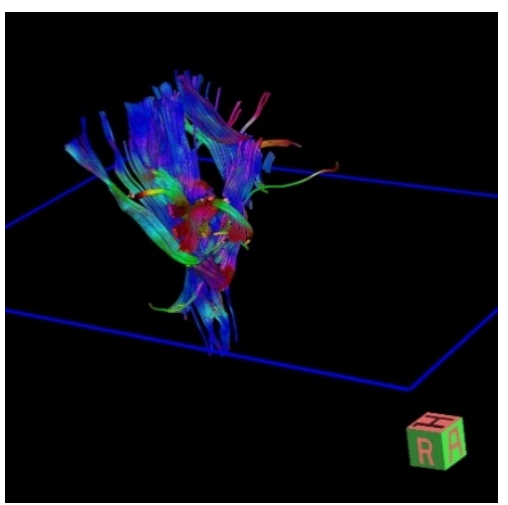

Şekil 4: Sol frontal yerleşimli oligoastrositom, sol Korona radiata süperior kesiminde (SKR) destrüksiyon

A) Doğrultusal renk kodlu haritada SKR lifleri seçilememekte ve yapılan ölçümlerde sol SKR'de simetriğine oranla izotropik difüzyona yakın belirgin derecede azalma (sağ-0.468, sol-0.053)

B) 3D traktografi görüntülerinde SKR anterior kesimde lifler seçilememektedir. 


\section{Bulgular}

Beyin tümörlü 26 hastada, lezyon tarafindaki 54 beyaz cevher yolağ1 ve kontralateral hemisferdeki normal beyaz cevher yolağ1 olmak üzere toplam 108 yolak değerlendirilmiștir. Değerlendirilen yolakları sınıflandırdığımızda 12'si ödem, 11'i yer değiştirme, 10'u infiltrasyon ve 21 'i destrüksiyon şeklinde etkilenmişlerdir.

Ödem, infiltrasyon ve destrüksiyon gruplarında $\Delta \mathrm{FA} \%$ değeri anlamlı olarak bulunmuştur. Yer değiştirme grubu için anlamlı $\Delta \mathrm{FA} \%$ değeri bulunmamıştır. Hem ödem hem de destrüksiyon grubundaki FA değeri yer değiştirmeden küçüktür (Tablo 1).

$\Delta \mathrm{FA} \%$ değerinin \%30'dan küçük olması infiltrasyon ve destrüksiyon ile ilişkili iken pozitif değerde olması ödem veya yer değiştirme ile ilişkili bulunmuştur (Tablo 2).

Ameliyat olan hastalar postoperatif dönemde beyin cerrahları tarafindan klinik olarak tekrar değerlendirilmiş olup preoperatif olarak DTG sonuçlarına göre özellikle ödem ve yer değiştirme grubuna dahil ettiğimiz hastalarda postoperatif ek nörolojik defisit gelişmediği bildirilmiştir.

\section{Tartıșma}

Beyin tümörlerinin rezeksiyonu öncesinde komşuluğundaki fonksiyonel anatomik yapılar ve beyaz cevher yolakları ile ilişkisinin detaylı bir şekilde ortaya koyulması gerekmektedir. Özellikle dominant hemisferdeki sensorimotor, konuşma ve kognitif fonksiyon merkezleri ile ilişkisi net bir şekilde belirlenmelidir $(1,6)$.

Yeni metodlardan biri olan DTG, beyinde beyaz cevher yolaklarının uzanim ve yönelimlerini ve bu yolakların niceliksel ve niteliksel bilgisini noninvaziv olarak in vivo sağlamasi nedeni ile önemli ve yeni bir görüntüleme tekniğidir $(2,6,8)$.

Witwer ve ark. (1), tümöre komşu beyaz cevher yolaklarını FA ve doğrultusal renk kodlu haritaları kullanarak ödem, yer değiştirme, infiltrasyon ve destrük- siyon olarak sınıflamışlardır. Diffüz oligodendrogliomu olan infiltrasyon grubuna dahil ettikleri 2 hastanın tümör rezeksiyon sınırından alınan çok sayıda patolojik örnekte beyaz cevher yolaklarinda neoplastik hücre infiltrasyonu gösterilmiştir. Beyaz cevher yolaklarında yer değiştirme izlenen hastaların hiçbirinde postoperatif nörolojik defisit gelişmediği hatta bir hastada ameliyat sonrasinda muhtemelen kortikospinal trakt (KST) üzerindeki bası etkisinin kalkmasına bağlı ameliyat öncesi var olan hemiparezide gerileme izlenmiştir. Ödem grubuna dahil ettikleri 2 hastada ameliyat sonrası afazi ve dizartride düzelme olduğu izlenmiştir. Sonuçlarına göre, DTG'nin tümör ile komşuluğundaki subkortikal beyaz cevher ilişkisini ortaya koymada kullanılabileceğini ve anormal görünen alanlarda anatomik olarak intakt yolakların olabileceğini savunmuşlardır (1).

Yen ve ark. (9), beyaz cevher yolaklarını Witwer metoduna göre kategorize etmişlerdir. FA değerlerini karşılaştırmak için mikst model analiz kullanmışlardır. Sonuçlarına göre $\Delta \mathrm{FA} \%$ değerini destrüksiyon grubunda anlamlı bulmuş olup bu bulguları ameliyat öncesi korunmuş beyaz cevher yolakları- nın belirlenmesinde kullanabileceklerini savunmuşlardır. Ayrıca hem ödem hem de destrüksiyon grubundaki FA değerini yer değiştirme grubundan düşük bulmuşlardır. $\Delta \mathrm{FA} \%$ 'nın 30\%'dan daha düşük olmasının destrüksiyon ile ilişkili olduğunu, pozitif $\Delta \mathrm{FA} \%$ 'nın ödem ve yer değiştirme ile ilişkili olduğunu ve $0 \%$ ile $-30 \%$ $\Delta \mathrm{FA} \%$ 'nın da yer değiştirme ve infiltrasyon ile ilişkili olduğunu savunmuşlardir (9).

Field ve ark. (10), beyaz cevher yolaklarını Yen ve ark. (9) gibi 4 paterne kategorize etmişlerdir. Farklı olarak FA haritasının yanı sıra ADC haritası ile ana eigen vektör yönünü kullanmışlardır. Yine farklı olarak yer değiştirme grubunda FA değerlerinin normal veya hafif düșük (<\%25), ADC değerlerinin normal veya hafif yüksek $(>\% 25)$ olabileceğini, ödem ve infiltrasyon paternlerinin her ikisinde de FA değerlerini düşük, ADC değerlerini yüksek kabul ederlerken ayrımı doğrultusal renk kodlu haritalardan yapmışlardır. Ödem paterninde; trakt normal lokalizasyon ve oryantasyonda iken renk tonlarinin normal, infiltrasyon paterninde renk tonunda farklilik olduğunu kabul ederek ayrımı yapmışlardır. Destrüksiyon paternini benzer şekilde

Tablo 1: Etkilenmiş taraftaki FA değerlerinin kontralateral taraf ile karşılaştırılması

\begin{tabular}{|l|l|l|l|}
\hline $\begin{array}{l}\text { Beyaz Cevher Etki- } \\
\text { lenme Tipi }\end{array}$ & Lezyon EMM \pm SE & Normal EMM \pm SE & $\mathrm{p}^{*}$ \\
\hline Ödem & $0.327 \pm 0.029$ & $0.385 \pm 0.029$ & 0.002 \\
\hline Yer Değiștirme & $0.607 \pm 0.025$ & $0.631 \pm 0.025$ & 0.201 \\
\hline İnfiltrasyon & $0.290 \pm 0.042$ & $0.615 \pm 0.042$ & 0.001 \\
\hline Destrüksiyon & $0.096 \pm 0.031$ & $0.615 \pm 0.042$ & $<0.001$ \\
\hline
\end{tabular}

*:Mikst etki ANOVA (varyans analizi), EMM: 'estimated marginal mean', SE: Standard error. ÖdemFA < Yer değiştirmeFA Yer değiştirmeFA > DestrüksiyonFA

Tablo 2: Beyaz Cevher Etkilenme Tipinin $\triangle F A \%$ şeklinde Hesaplanması (strata analizi)

\begin{tabular}{|l|l|l|l|l|}
\hline \multirow{2}{*}{$\begin{array}{l}\text { Beyaz Cevher Etki- } \\
\text { lenme Tipi }\end{array}$} & \multicolumn{3}{|c|}{$\Delta$ FA\% strata } & \multirow{2}{*}{ p* $^{*}$} \\
\cline { 2 - 4 } & $<-30$ & $-30-0$ & $>0$ & \\
\hline Ödem & $9(18.4 \%)$ & $1(100 \%)$ & $2(50 \%)$ & \multirow{2}{*}{0.055} \\
\hline Yer Değiștirme & $9(18.4 \%)$ & $0(0 \%)$ & $2(50 \%)$ & \\
\hline Infiltrasyon & $10(20.4 \%)$ & $0(0 \%)$ & $0(0 \%)$ & $0(0 \%)$ \\
\hline Destrüksiyon & $21(42.9 \%)$ & $0(0 \%)$ & & \\
\hline
\end{tabular}


sınıflandırılmıştır. Yer değiştirme, ödem ve infiltrasyon paternlerinde FA değerleri ile ADC değerleri arasında ters ilişki olduğunu bulmuşlardır. Sonuç olarak preoperatif olarak tümör ile komşuluğundaki beyaz cevher traktlarının ilişkisinin DTG ile ortaya koyulabileceğinin ve preoperatif planlamada en yararlı paternlerin yer değiştirme ve destrüksiyon paternleri olduğunu savunmuşlardır (10).

Bizim çalışmamızda beyaz cevher yolakları Field ve arkadaşlarının (10) sınıflandırdığı gibi kategorize edilmiş olup doğrultusal renk kodlu harita yanı sıra kantitatif olarak yalnızca FA değerleri kullanılmıştır. Yen ve arkadaşlarında (9) olduğu gibi $\Delta \mathrm{FA} \%$ değeri hesaplanmış olup farklı olarak bizim çalışmamızda destrüksiyon yanı sıra ödem ve infiltrasyon grubunda da $\Delta \mathrm{FA} \%$ değeri anlamlı bulunmuştur. Bu farklılığın beyaz cevher yolaklarını sınıflandirırken Yen ve arkadaşlarından (9) farklı olarak ödem ve infiltrasyon grubunda da FA değişiminin olabileceğini kabul ettiğimizden kaynaklandığını düşünmekteyiz. Benzer şekilde hem ödem hem de destrüksiyon grubundaki FA değerlerini yer değiştirmeden küçük olarak bulduk. Farklı olarak biz infiltrasyon grubundaki FA değerlerini de yer değiştirme grubundaki FA değerlerinden küçük bulduk. Bu farklılığın da aynı nedene bağlı olduğunu düşünmekteyiz. Ayrıca bizim çalışmamızda da Yen ve arkadaşlarınınki 0 kadar yüksek olmasa da benzer şekilde
$\Delta \mathrm{FA} \%$ 'nın -30\%'dan daha düşük olması destrüksiyon ile ilişkili, pozitif $\Delta \mathrm{FA} \%$ ödem ve yer değiştirme ile ilişkili bulunmuştur. Farklı olarak bizde $0 \%$ ile $-30 \% \Delta \mathrm{FA} \%$ ödem ile ilişkili bulunmuştur. Ancak artan olgu say1ları ve bu konudaki farklı çalışmalar ile birlikte istatiksel anlamlllı̆̆ın belirginleşeceği ve bu çelişkinin azalacağını düşünmekteyiz.

İliescu ve ark. (11), beyaz cevher etkilenim şekillerini yer değiştirme, ödem, infiltrasyon ve destrüksiyon olarak karakterize etmişlerdir. Bizim çalışmamızdan farklı olarak ödem grubunu Witwer metoduna göre yalnızca normal anizotropi ve oryantasyon gösteren ancak anormal T2 hiperintens alana sahip olanlardan oluşturmuşlardır. İnfiltrasyon grubunu ise anizotropide düşüklük gösteren ancak oryantasyon haritasında seçilebilen yolaklar olarak oluşturmuşlardır. Sonuçlarına göre yer değiştirme grubuna dahil ettikleri hastalarda ek nörolojik defisit gelişmediği hatta bir hastada yer değiştiren KST'ye göre ameliyat öncesi cerrahi prosedürü değiştirerek, yapılan ameliyat sonrasında hastanın nörolojik muayene bulgularında iyileşme olduğu kaydedilmiştir (11). Konvansiyonel görüntülerde anormal görünen alanlarda anatomik olarak intakt yolakların bulunabileceğini beyaz cevherin DTG ile değerlendirilerek bulguların cerrahi planlamada ve güvenli rezeksiyon alanının belirlenmesinde yararlı olacağını belirterek Witwer ile aynı görüşü savunmuşlardır (11).

Bizim çalışmamızda da postoperatif dönemde hastalar beyin cerrahları tarafindan klinik olarak tekrar değerlendirilmiş olup postoperatif ek nörolojik defisit gelişmemiş olduğu bildirilmiştir. Sonuçlarımız klinik olarak da desteklenmiş olup cerrahi planlamada DTG'nin tümör ile beyaz cevher yolakları ilişkisini ortaya koymada kullanılabilir bir yöntem olduğunu göstermektedir.

Mori ve ark. (12), tümör hücreleri tarafindan infiltre edilen alandaki FA değerlerinin peritümöral ödemden daha düşük olduğunu bulmuşlardır $(1,12)$. Bizim çalışmamızda da anlamlı düzeyde olmasa da infiltrasyon grubundaki FA değerinin ödemden daha düşük olduğu bulunmuştur.

\section{Sonuç}

Sonuçlarımız, DTG verilerinin kalitatif ve kantitatif analizi ile beyaz cevher yolaklarının ameliyat öncesi değerlendirilebileceğini ve etkin bir cerrahi planlamayı mümkün kılabileceğini göstermiştir. En uygun tedavi planının gerçekleşmesi ile nüks olasıllı̆̆ının azalması beraberinde vital serebral fonksiyonların korunması ile morbitidenin azalması ve kaliteli yaşam şansının artması sağlanabilecektir. 


\section{KAYNAKLAR}

1. Witwer BP, Moftakhar R, Hasan KH, et al. Diffusion-Tensor Imaging of White Matter Tracts in Patients with Cerebral Neoplasm. J Neurosurg 2002;97:568-575.

2. Itagiba VGA, Borges R, Cruz Jr LCH, et al. Use of diffusion tensor magnetic resonance imaging in the assessment of patterns of white matter involvement in patients with brain tumors: is it useful in the differential diagnosis?. Radiol Bras. 2010;43:362-368.

3. Sternberg EJ, Lipton ML, Burns J. Utility of Diffusion Tensor Imaging in Evaluation of thePeritumoral Region in Patients with Primary and Metastatic Brain Tumors. AJNR Am J Neuroradiol 2014;35:439-444.

4. Bryan J. Laundre, Brian J. Jellison, Behnam Badie, et al. Diffusion Tensor Imaging of the Corticospinal Tract before and after Mass Resection as Correlated with Clinical
Motor Findings: Preliminary Data. AJNR Am J Neuroradiol 2005;26:791-796.

5. Hagmann P, Jonasson L, Maeder P, et al. Understanding Diffusion MR Imaging Tecniques: From Scalar Diffusion Weighted Imaging to Diffusion Tensor Imaging and Beyond. Radiographics 2006;26:205223

6. Ibrahim AS, Gomaa M, Sakr H, et al. Role of diffusion tensor imaging in characterization and preoperative planning of brain neoplasms. The Egyptian Journal of Radiology and Nuclear Medicine 2013;44:297-307.

7. Price SJ, Gillard JH. Imaging Biomarkers of brain Tumour Margin and Tumour Invasion. Br J Radiol 2011;84:159-167

8. Cruz LCH, Sorensen AG. Diffusion Tensor Magnetic Resonance Imaging of Brain Tumors. Magn Reson Imaging Clin N 2006;14:183-202
9. Yen PS, Teo BT, Chiu CH, et al. White Matter Tract Involvement in Brain Tumors: A Diffusion Tensor Imaging Analysis. Surgical Neurology 2009;72:464-469

10. Field AS, Alexander AL, Wu Y, et al. Diffusion Tensor Eigenvector Directional Color Imaging Patterns in the Evaluation of Cerebral white Matter Tracts Altered by Tumor. J Magn Reson Imag 2004;20:555562

11. Iliescu B, Negru D, Poeta I. MR Tractography for Preoperative planning in Patients with Cerebral Tumors in Eloquent Areas. Rom Neurosurg 2010;4:413-420

12. Mori S, Frederiksen K, Van Zijl PCM, et al. Brain white matter anatomy of tumor patients evaluated with diffusion tensor imaging. Ann Neurol 2002;51:377-380.. 